\title{
ELEMENTOS PARA UMA ANÁLISE DA REGIONALIZAÇÃO VERSUS GLOBALIZAÇÃO A PARTIR DA PERSPECTIVA DAS CADEIAS MERCANTIS GLOBAIS ${ }^{1}$
}

Lairton Marcelo Comerlatto²

\section{Resumo}

Este trabalho tem por objetivo trazer modestas contribuições e elementos que ajudem a compreender a relação entre o local/regional e o global. Neste sentido, mostram-se duas formas de se analisar esta relação: a do "desenvolvimento local e endógeno"; e a da "globalização". Como uma forma alternativa para analisar tal relação, utiliza-se a perspectiva das cadeias mercantis globais. Desse modo, quais as possíveis contribuições do marco conceitual das cadeias mercantis globais para o debate local/ regional versus o global? Em que medida e de que forma as regiões são incorporadas à uma, ou mais de uma cadeia mercantil global? Qual o significado dessa inserção para a região? Assim formulada, a problemática deste trabalho reflete a compreensão de que, em diferentes casos, o desenvolvimento amplo de processos observados e manifestados localmente requer considerar tais processos como partes de dimensões que transcendem significativamente as dimensões locais.

Palavras Chave: local/regional; global; globalização; inserção; cadeias mercantis globais.

Classificação JEL: R10; R38

Trabalho desenvolvido no Programa de Pós-Graduação em Geografia da Universidade Federal de Santa Catarina, com apoio do Conselho Nacional de Desenvolvimento Científico e Tecnológico - CNPq/Brasil.

2 Doutorando do Programa de Pós-Graduação em Geografia da Universidade Federal de Santa Catarina (lairton_comerlatto@yahoo.com.br). 


\section{INTRODUÇÃO}

Identificando duas das formas de analisar a relação local/regional versus o global, este artigo busca trazer uma terceira forma de analisar tal relação. A primeira das formas de analisar esse debate refere-se a chamada globalização, que de acordo com diversos autores, é responsável por grandes desafios em diferentes ambientes locais/regionais e em diversas circunstâncias, por uma percepção tão forte que chega a ensejar reflexões e iniciativas de políticas e em por iniciativas de políticas, voltadas para o desenvolvimento, em que a dimensão local das medidas e os impulsos endógenos têm ocupado posição de destaque. Estes últimos, entendidos aqui como a segunda forma de analisar o debate.

Uma terceira forma de fazer a analise sobre essa discussão, refere-se à perspectiva das cadeias mercantis globais, ou cadeias globais do valor, florescida originalmente em abordagens históricas sobre o capitalismo, centradas na idéia de sistema mundial e que, atualmente tem sido usado na busca de entendimento as desigualdades de desenvolvimento sócio-territoriais. Uma característica dessa perspectiva, é que ela enfatiza o caráter sistêmico e também histórico dos diferentes processos econômicos e sociais, com ênfase nas dimensões globais. Dessa forma, esta perspectiva pode ser compreendida, como uma crítica ao chamado desenvolvimento local/regional "endógeno".

Os questionamentos que norteiam este trabalho são: Quais as possíveis contribuições do marco conceitual das cadeias mercantis globais para o debate local/regional versus o global? Em que medida e de que forma as regiões são incorporadas à uma, ou mais de uma cadeia mercantil global? Qual o significado dessa inserção para a região?

Assim, a primeira parte deste artigo inicia discorrendo sobre a chamada globalização e o que este fenômeno representa para as regiões. Na segunda parte, analisa-se o desenvolvimento local-regional endógeno, destacando as limitações dessa análise regionalista para dar conta das realidades locais/ regionais inseridas em dinâmicas socioeconômicas amplas, estruturais. Em seguida, discorre-se sobre as cadeias mercantis globais como um marco analítico para o estudo sobre as dinâmicas locais/regionais. 


\section{A GLOBALIZAÇÃO E SUAS IMPLICAÇÕES}

O fenômeno conhecido como globalização pode ser interpretado sob diversos aspectos: cultural, tecnológico, econômico, por exemplo. O que mais tem chamado a atenção, talvez seja o aspecto econômico, já que abrange três perspectivas: a produtiva, a comercial e a financeira.

No que diz respeito às perspectivas produtiva e comercial, pode-se identificar uma "homogeneização" das estruturas de produção e de comercialização em escala ampla, em razão da intensidade das trocas estimuladas pela abertura comercial dos países não desenvolvidos - principalmente sob a influência/ingerência de instituições supra nacionais (como o FMI e o Banco Mundial).

A perspectiva financeira da globalização refere-se ao aumento no volume e na velocidade da circulação de recursos financeiros (BAUMANN, 1996). Para Arrighi (2003, p. 14) a expressão "globalização financeira passou a ser utilizada para denotar o processo de (re)integração dos mercados nacionais num mercado global único e amplamente desregulado". Essa designação teria sido, em primeiro lugar, introduzida para denotar "uma mudança de um sistema global (hierarquicamente organizado e amplamente controlado politicamente pelos Estados Unidos) para um outro sistema mais descentralizado e coordenado pelo mercado, tornando as condições financeiras do capitalismo largamente mais voláteis e instáveis" (HARVEY, 1995, p. 8, apud ARRIGHI, 2003, p, 14). Ou seja, “a idéia da globalização foi, desde o início, articulada com a idéia da intensa competição inter-estatal pelos capitais crescentemente voláteis, e a conseqüente subordinação rígida da maior parte dos estados (inclusive dos Estados Unidos) aos ditames das agências capitalistas privadas" (ARRIGHI, 2003, p, 14).

Todavia, os capitais não se movem só conforme a lógica especulativa, envolvendo arbitragem entre os diferenciais de juros. Movem-se, também, na forma de investimentos estrangeiros diretos (IED), o que remete à percepção "produtiva" da globalização.

De fato, entre as principais características do processo de globalização destaca-se, de um lado, o crescimento exponencial dos investimentos estrangeiros diretos (IED) e, de outro lado - e em conexão com o primeiro aspecto -, o surgimento de estruturas de oferta internacional, fortemente 
concentradas. Tudo isso ocorre paralelamente ao aprofundamento do oligopolizado caráter dos negócios, referindo-se à multiplicação das fusões e aquisições em escala internacional. As empresas multinacionais (EMN) se constituem nos agentes básicos desse processo.

Os IED figuram, assim, como um importante aspecto na trasnacionalização da produção, sua expansão pode adquirir um significado maior do que a própria magnitude do comércio em escala mundial.

Em suma, o que tem sido chamado de globalização engloba aspectos que vão desde a mobilidade exacerbada do capital, principalmente na forma de IED feitos pelas EMN, até o aumento da concorrência em escala mundial decorrente do processo de deslocalização das unidades produtivas das empresas ou através da liberalização do comércio mundial com exterior em diferentes países. Como vimos, a multinacionalização da produção é decorrente, entre outros fatores, das desigualdades entre países. Desigualdades que se refletem, por exemplo, nas diferenças entre os salários, o que, por sua vez, afetam diretamente os custos de produção. Dessa forma, esses movimentos do capital representam grandes desafios para países, regiões, localidades, setores, trabalhadores e empresas.

Com efeito, o vocábulo "globalização", designando processos econômicos em escala internacional, remete ao problema das desigualdades entre economias nacionais, no qual um importante aspecto a ser considerado é o referente ao já assinalado problema dos fluxos dos investimentos externos diretos (IED). O grande capital internacional constitui protagonista chave nessa discussão, e os Estados nacionais aparecem como que enredados. Isso não é desprovido de conseqüências: "não surpreende que governos se tornem quase reféns de empresas multinacionais. Atrair investimentos estrangeiros impõe-se como a palavra de ordem e, por conseguinte, deflagra-se competição encarniçada visando seduzir o grande capital". (LINS, 2001, p. 81).

Como resultado dessa competição, as regiões se inserem na economia-mundial de forma distinta, com desenvolvimentos econômicos e sociais distintos, de maneira que o desenvolvimento dos territórios se dá, igualmente, de forma desigual. Essas desigualdades, vinculadas a desenvolvimentos tão díspares, parecem, assim, ser características do capitalismo histórico.

Não admira, portanto, que os efeitos da "globalização" no surgimento ou aprofundamento das desigualdades entre economias nacionais e/ou 
regiões dentro destas, venham, nas últimas décadas, atraindo a atenção de numerosos pesquisadores de diferentes correntes do pensamento científico. Uma ilustração refere-se a Georges Benko, que aborda o que é por ele designado como "dualidade global-local”: para Benko (1996), o vocábulo "globalização" recobre também, entre outros aspectos, a tendência atual das grandes empresas a delegar uma parcela do seu poder às filiais dispersas nos quatro cantos do mundo. Para melhorar sua competitividade, as multinacionais confiam suas filiais (...) [a] administradores autóctones, mais aptos a perceber as especificidades locais nos métodos de gestão e produção" (Op. cit., p. 67).

Merece realce, principalmente, a proposição de Benko (1996), do conceito de "globalidade dinâmica local", que serve de referência "para analisar a abertura dos sistemas locais para o seu milieu" (BENKO, 1996, p. 76, grifos do autor). Essa abertura acontece de diferentes formas, a mais corrente das quais é a intensificação das trocas com outros territórios, dinâmica por meio da qual se pode captar os processos local-regionais e processos mais amplos. Particularmente interessante é o conceito de "globalização regional", utilizado por Benko (1996), que mostra que o desenvolvimento de uma região implica muito mais do que as vantagens auferidas com a intensificação das trocas interterritoriais. É preciso que o sistema local envolva o seu hinterland: é principalmente assim "que este encontra o meio de retomar eficazmente seu desenvolvimento" (BENKO, 1996, p. 76, grifos do autor). Ou seja, “estendendo o próprio sistema de organização a espaços 'novos' e diferentes, o ambiente local é levado a inventar e a utilizar novas estruturas econômicas e territoriais" (Ibib).

Desse modo, a questão do desenvolvimento regional na globalização pode ser focalizada de dois modos:

De um lado, a economia global pode ser vista como um mosaico de sistemas de produção regionais especializados, possuindo cada qual sua própria rede densa de acordos de trocas, no interior da região, e um funcionamento específico do mercado local do trabalho. De outro, o mesmo mosaico se insere no entrelace planetário de ligações interindustriais, de fluxos de investimentos e de migrações de população (BENKO, 1996, p. 70). 
Ou seja, a globalização, embora tenha espraiado o fenômeno industrial, tem significado desigualdades, hierarquias, assimetrias, o que em si mesmo requer análise interpretativa. Ora, Kaplisnky (2000) considera que só no marco de abordagens sistêmicas, ou seja, que considerem o funcionamento de estruturas amplas, se pode dar conta da persistência das desigualdades no âmbito da globalização. Cabe ressaltar que a percepção sobre os enormes desafios representados pela globalização para setores produtivos, territórios e atores sociais, devido ao aumento da concorrência e à exacerbação da mobilidade do capital, entre outros fatores, produziu reações. Nesse contexto ganhou corpo um tipo de abordagem sobre o desenvolvimento local-regional que salienta os atributos dos próprios territórios como aptos a permitir o enfrentamento desses desafios: é a abordagem conhecida como do desenvolvimento local e endógeno, tornada quase paradigmática no período recente. A próxima seção tece considerações sobre aspectos dessa abordagem, procurando mostrar o seu escopo e suas limitações.

\section{O LOCAL E O PARADIGMA DO DESENVOLVIMENTO EN- DÓGENO}

$\mathrm{Na}$ esteira do debate sobre desenvolvimento, ganhou fôlego a análise do "desenvolvimento endógeno", que trás consigo a ideia de que as possibilidades de desenvolvimento estariam apenas vinculadas às próprias condições dos ambientes locais/regionais, ou seja, vinculada à sua própria história e aos seus atributos específicos.

Essa ideia ganhou força, ao que parece, na esteira de diferentes processos, entre os quais figuram: a) a descentralização das funções do Estado, no bojo das grandes mudanças que ocorreram no funcionamento deste durante as últimas décadas; b) as frustrações com a promoção do desenvolvimento local-regional de forma mais ou menos centralizada, como observado em diferentes países; e c) a visibilidade adquirida pelas experiências ao estilo dos clusters e distritos industriais europeus, sobretudo (mas não só) no caso italiano ${ }^{3}$.

Com base em Schmitz ( 1995$)$, Clusters são aglomerados produtivos, caracterizados pela inovação, especialização, e, de certa forma, pela cooperação, essenciais para a competição fora dos mercados locais. Distritos industriais são clusters que apresentam "eficiência coletiva", isto é, a articulação entre economias externas e ação conjunta, ou cooperação. 
O primeiro aspecto, relativo à descentralização das funções públicas, deve ser colocada na perspectiva das mudanças no papel do Estado, nas últimas décadas. Nesse papel figura, historicamente, o planejamento e a promoção do desenvolvimento local-regional. Essas atribuições ganharam maior relevância, a partir do Segundo Pós-Guerra, na esteira das assim chamadas políticas keynesianas e, em certo sentido, com inspiração no New Deal norte-americano. Contudo, principalmente a partir dos anos 1980, as atribuições de planejar e promover o desenvolvimento sofreram alterações em diferentes países. Em vários casos, elas quase desapareceram da agenda estatal, sobretudo nos países periféricos e semiperiféricos, e, quase sempre, foram deixadas de lado pelos governos centrais. De fato, observou-se forte tendência à descentralização dessas funções, um processo que se transformou num "quase paradigma, sendo que muitas vezes tratou-se mesmo de necessidade, já que as restrições de ordem técnico/financeira e/ou a reorientação na conduta pública diminuíram a capacidade do Estado [central] para atuar na esfera local-regional" (LINS, 2003, p. 3).

Graças, em parte, a essa descentralização, ganhou força no processo de desenvolvimento a noção de desenvolvimento local, disseminando, a partir dos anos 1980, o uso de expressões como "desenvolvimento endógeno" (BENKO; LIPIETZ, 1994) e "industrialização difusa" (PECQUEUR e SILVA, 1988). Pouco a pouco uma nova ortodoxia na reflexão sobre o desenvolvimento socioespacial - uma outra ortodoxia, ligada aos trabalhos de François Perroux (PERROUX, 1967), vinculara-se à noção de pólo de crescimento, foco (esperado) de irradiação de crescimento e desenvolvimento - ganhou terreno, um processo perpassado pela crença nas condições locais para impulsionar o desenvolvimento.

As experiências em termos de dinâmica produtiva territorializada, em clusters ou em aglomerações do tipo distrito industrial, também contribuíram para o fortalecimento da idéia de desenvolvimento endógeno, como se falou. Segundo Garofoli (1994), as características mais importantes desses aglomerados correspondem a uma forte especialização produtiva ao nível local, com produção respondendo por boa parte da respectiva produção nacional; a uma acentuada divisão do trabalho entre as empresas do aglomerado; à inexistência, em grande parte dos casos, de uma empresa líder, mas presença de uma multiplicidade de pequenas e médias empresas; há trabalhadores com diferentes níveis de qualificação (mas com destaque 
para a elevada qualificação) no nível local; a contatos pessoais diretos, especialmente entre fornecedores e as empresas operadoras do sistema local, o que favorece a difusão dos melhoramentos técnicos e organizacionais; e também à flexibilidade produtiva dentro do sistema.

O tema do desenvolvimento local e endógeno surge, assim, da observação do que parece ser uma resposta das comunidades locais - pelo menos é dessa forma que aparece referido na literatura - aos desafios colocados pelo processo em curso - de globalização -, que resultou em fechamento de empresas, desindustrialização e aumento do desemprego (VAZQUEZ BARQUERO, 2001, p. 25). Os "endogenistas" consideram, de fato, que "o desenvolvimento econômico ocorre em conseqüência da utilização do potencial e do excedente gerado localmente e, eventualmente, pela atração de recursos externos, assim como pela incorporação das economias externas ocultas nos processos produtivos" (VÁZQUEZ BARQUERO, 2001, p. 19, grifos nossos). Além disso, seria "preciso ativar os fatores determinantes dos processos de acumulação de capital [para] neutralizar as tendências de um estado estacionário" (Ibid). Fatores esses que dizem respeito à "criação e difusão de inovações no sistema produtivo, à organização flexível da produção, à geração de economias de aglomeração e de economias de diversidade nas cidades e o fortalecimento das instituições" (Ibid).

No marco de reflexão sobre o desenvolvimento endógeno, as políticas de promoção local privilegiam aspectos como a difusão das informações e do conhecimento, o fortalecimento das empresas e a formação de redes, a articulação do território e o resgate das economias externas ocultas. É importante destacar que essas políticas de desenvolvimento associam-se a uma abordagem "de baixo para cima": são os atores locais que desempenham as funções centrais, dizendo respeito à definição, execução e ao controle das medidas e iniciativas. Em alguns casos, os atores locais organizam-se em redes, que servem de instrumentos para conhecer e entender a dinâmica local do sistema produtivo e das instituições, assim como unir as iniciativas e executar as ações que formam a estratégia de desenvolvimento local (VAZQUEZ BARQUERO, 2001, p. 26-29).

Assim, a idéia de desenvolvimento local e endógeno, para os "endogenistas", é uma interpretação que permite, por exemplo, explicar os processos de acumulação de capital e identificar os mecanismos sociais e 
econômicos que contribuem para o aumento da produtividade e competitividade de cidades e regiões.

O substrato de tal possível mudança estrutural é o fato de que, na perspectiva dos endogenistas", os locais e regiões dispõem de recursos (econômicos, humanos, institucionais e culturais, bem como de economias de escala não aproveitadas) que possibilitam a formação de um potencial de desenvolvimento endógeno cujo uso poderia garantir a criação de riquezas e a melhoria do bem-estar local. São geralmente sublinhados, entre os traços que favorecem o desenvolvimento local-endógeno, a disponibilidade de mão-de-obra qualificada com baixos índices de conflitos trabalhistas e a capacidade empresarial no tocante à inovação e às mudanças, favorecendo assim a acumulação de capital nos sistemas produtivos locais.

Assinala-se igualmente que os fatores que favorecem a utilização do potencial de desenvolvimento local são melhor aproveitados nas regiões onde os mecanismos de regulação funcionam com mais eficiência. Ou seja, o modo de organização da produção, as estruturas familiar, social e cultural, além dos códigos de conduta, podem facilitar (ou limitar) a dinâmica econômica da região (LINS, 2006a).

Apesar do forte apelo do enfoque em termos de desenvolvimento endógeno, essa opção analítica - e seus desdobramentos em termos de formulação de políticas - não são imunes a críticas. Em primeiro lugar, a flexibilidade - marca do sistema de aglomeração produtiva do tipo cluster, conforme exaltado na literatura, -, por exemplo, não pode ser vista como uma manifestação evolutiva do sistema de produção capitalista. Como mostram Amin e Robins (1994), a indústria capitalista sempre aliou flexibilidade e rigidez (traço característico do modelo de produção fordista), e o que se assiste nos dias atuais, na produção industrial, vem a ser uma combinação destes dois fatores.

Por outro lado, envolvendo as condições sócio-produtivas mesmo nas experiências paradigmáticas, estudo de Capello (1988), mostra, para a década de setenta, as disparidades entre o crescimento da produtividade e a relação entre produtividade-salário em localidades que compõe a Terceira Itália. Baseados nesse estudo, Amin e Robins (1994) comentam que apenas de modo muito vago se pode dizer que esses locais se articulam verdadeiramente em torno de um sistema industrial e que as configurações existentes representam condições sociais inegavelmente positivas. 
Outro aspecto é que, embora a amplitude do conceito de distrito industrial consiga explicar as relações sinérgicas entre as empresas na dinâmica do desenvolvimento de certa localidade, a banalização do uso dessa expressão é também objeto de críticas. O motivo central é que essa vulgarização vem acompanhada de uma tentativa de demonstrar que essa forma de desenvolvimento (dita flexível), constitui a emergência de um novo regime de acumulação capitalista pós-fordista. Há evidência de uma tal banalização quando, por exemplo, como percebido por Amin e Robins (Op. cit), Sabel (1989) põe sob um mesmo guarda-chuva teórico configurações como Silicon Valley e Route 128 (complexos de alta tecnologia), de uma parte, e distritos industriais de base artesanal, como os da Terceira Itália, de outra parte.

Igualmente digno de realce, é o fato de que o enfoque sobre desenvolvimento nos termos do debate sobre distritos industriais, (ou clusters de um modo geral), remete às reflexões sobre as mutações da geografia da acumulação, ou seja, no período contemporâneo, sobre a reestruturação do espaço e do território numa suposta transição para o pós-fordismo (AMIN; ROBINS, op. cit.). O problema é que, nesse processo, o próprio território passa a ser visto como o grande regulador autônomo das relações, dando a entender que o Estado, sempre que possível, pode (e deve) ser substituído no processo regulatório que engloba projetos sociais e políticos. Em outras palavras, "personifica-se, fetichiza-se e reifica-se o território, ao preconizar que o mesmo tenha poder de decisão, desde que dotado do adequado grau de densidade institucional e comunitária. À ação pública [nacional] caberia apenas animá-lo e sensibilizá-lo, construindo confiança e consensos duradouros" (BRANDÃO, 2004, p. 58). Ora, o território não pode ser visto como um "sujeito coletivo", autônomo, com capacidade de construir seu próprio futuro. Sequer a comunidade (os atores sociais locais) que habita tal território pode ser, ela mesma, a única responsável pelo desenvolvimento. Como adverte Brandão (2004), o território "é uma construção social conflituosa. Uma produção coletiva, dinâmica, multidimensional, com trajetória histórica em aberto"(Op. cit., p. 60). Portanto, o desenvolvimento territorial revela-se dependente de determinados contextos, situações e equilíbrio de poderes.

Cabe mencionar a respeito disso a advertência de Lins (2006a) sobre as limitações da regulação em escala local:

Nas aglomerações produtivas, as possibilidades de governança local não transcendem, em regra, os problemas ligados a inovações, sistemas de 
informação, um certo controle do mercado e ações envolvendo a integração entre instituições e agentes econômicos (..) Trata-se, assim de um arco regulatório com intervenções de alcance somente parcial (...) [A] regulação local não pode ser considerada capaz de contrabalançar a regulação nacional e, menos ainda, de sobrepor-se a esta (Op. cit., p. 163).

Com efeito, além da comunidade local - muitas vezes marcada pela luta de classes -, o desenvolvimento territorial também depende, e acusa fortemente a presença, de interesses de empresas multinacionais, em diferentes experiências e circunstâncias. Estas empresas figurariam, assim, como verdadeiros “atores e artífices" não só da economia mundial, mas também da territorial, dando a entender que o desenvolvimento desigual dos territórios se mostra como um aspecto estratégico do desenvolvimento das multinacionias.

Portanto, apesar do grande apelo que o paradigma do desenvolvimento endógeno representa, o correspondente enfoque revela-se limitado para a observação do desenvolvimento local-regional sob uma ótica mais ampla. Essa ótica privilegia o entendimento sobre o desenvolvimento local-regional que considera a articulação dos fatores internos de cada local ou região à sua participação em redes de comércio e produção ao nível internacional as cadeias mercantis globais. Têm razão, assim, Amin e Robins (Op. cit.) quando consideram que, "as economias locais só podem ser encaradas como malhas de uma rede econômica global (...). Se tivermos presente que esse campo global é moldado e transformado por formidáveis relações de poder, então a amplitude da autonomia e da regeneração locais vê-se substancialmente reduzidas" (p. 98).

\section{CADEIAS MERCANTIS GLOBAIS: DESDOBRAMENTOS E INCORPORAÇÕES}

A perspectiva das cadeias mercantis globais faz parte da abordagem conceitual conhecida como Análise dos Sistemas-Mundo ${ }^{4}$, que tem como principais expoentes Immanuel Wallerstein, Giovanni Arrighi, Fernand Braudel e Terence Hopkins.

Os autores em questão assinalam que a melhor forma de "conceber" a existência de uma cadeia assim designada, identificando-a e delimitando-a,

Ver Braudel (1897, 1989, 1992, 1998); Hopkins e Wallerstein (1986, 1987, 1994); Wallerstein (1979, 1984, 1998). 
é partir de uma mercadoria terminada, pronta para ser encaminhada para a comercialização final, e remontar toda a seqüência de operações cujo resultado último é essa mercadoria. Esse procedimento implica levar em conta os diferentes segmentos e sub-segmentos (elos e sub-elos) da seqüência até serem alcançadas as atividades ligadas às matérias-primas iniciais.

Colocar o assunto nesses termos favorece a percepção de que tais cadeias perpassam as fronteiras dos Estados nacionais, interconectando-os através de relações mercantis. Daí poder-se considerar que "uma economia-mundo ${ }^{5}$ apresenta-se como estrutura em que o sistema inter-estatal é vazado por cadeias mercantis, as últimas constituindo-se no elemento básico de coesão daquela totalidade social e, simultaneamente, no parâmetro que, tendo em vista a abrangência geográfica das interações, permite a delimitação do espaço interno à primeira" (LINS, 2005, p. 4).

A economia-mundo capitalista, que teve origem na Europa Ocidental no início do século XVI, abrigava e favorecia os mecanismos de uma “acumulação sem fim de capital” (HOPKINS; WALLERSTEIN, 1987, p. 764). Esse processo de acumulação “envolveu expansão geográfica impelida por processos internos, pois o avanço deu-se em movimentos cíclicos de incorporação de novas áreas em resposta às necessidades de desdobramento espacial das cadeias mercantis" (Op. cit., 1987, p. 765).

O processo de incorporação de novas áreas à economia-mundo capitalista modelou uma estrutura hierarquizada integrada por áreas centrais, semiperiféricas e periféricas. Cada uma dessas áreas ocupava - e segue ocupando - posições mais ou menos específicas nas cadeias mercantis e no sistema inter-estatal. Baseado em Wallerstein, Lins (2004) refere-se ao processo de incorporação como segue:

(...) no século XVI, o noroeste europeu desempenhava o papel de centro, a Europa mediterrânica, o de semiperiferia, e a Europa do leste e o Hemisfério Ocidental (o mundo atlântico), o de periferia. Até as primeiras décadas do século XVIII, nem a Rússia, o Império Otomano, o subcontinente indiano ou a África Ocidental participaram da nova totalidade. Permaneceram como áreas externas, quer dizer, áreas com as quais o comércio não representava, para a economia-mundo

Ver Braudel (1897, 1989, 1992, 1998) e Wallerstein (1979, 1984, 1998). 
européia, um fluxo de mercadorias essenciais. A incorporação desses territórios só ocorreria a partir da primeira metade do século XVIII, já sob a égide de um capitalismo industrial, tendo essa "internalização" respondido ás exigências da economia-mundo capitalista naquele período: o aumento do raio de ação das cadeias mercantis tornou-se uma necessidade à acumulação de capital. Seguindo o mesmo tipo de lógica, $\mathrm{o}$ restante da África e a Ásia registraram a sua absorção como periferias somente no decorrer do século XIX (Op. cit., p. 5).

Essa incorporação sempre se traduziu em acréscimos de novas e vastas periferias, ou seja, áreas em que as atividades envolvidas em cadeias mercantis caracterizavam-se quase invariavelmente como "inferiores", no que se refere à tecnologia, à organização produtiva, às formas de processo de trabalho, e à qualificação da mão-de-obra, com repercussões diretas no tocante às remunerações ou, de uma forma geral, das recompensas referentes a níveis de lucros e salários, por exemplo. Além disso, a incorporação das áreas periféricas acabou por atrofiar, em diferentes casos, as atividades desde sempre praticadas nessas áreas. A agricultura de subsistência, a indústria doméstica, o artesanato, de um modo geral, acusaram o impacto das transformações ocasionadas pela dinâmica da incorporação.

Contudo, também as áreas centrais e semiperiféricas foram afetadas pelo processo de incorporação capitalista. Está-se falando, desse modo, das transferências de atividades produtivas entre regiões pertencentes à própria zona central da economia-mundo ou situadas nas suas proximidades, ou mesmo destas para zonas periféricas e/ou semiperiféricas. Durante o século $\mathrm{XX}$, o processo de transferência de parques fabris - a indústria automotiva, a indústria têxtil, etc,-- para a América Latina e para o leste asiático, por exemplo, pode ser interpretado como um deslocamento das atividades de produção desde o centro da economia-mundo (Europa, EUA e Japão).

Para Wallersein, as desigualdades socioespaciais são, nesses termos, fruto do desdobramento geográfico das cadeias mercantis e do alcance de diferentes países e regiões pela divisão espacial do trabalho que estrutura, como uma espinha dorsal, essas redes produtivas. (LINS, 2004. p. 10). Porém, como ressalta Lins (2004), apesar do grande apelo que o enfoque do sistema-mundo tem para a explicação das desigualdades sócio-espaciais, não se pode - ou se deve - tomá-lo como absoluto. O próprio Braudel, uns 
dos autores "pilares" da Economia Política dos Sistemas-mundo, faz em sua obra advertências nesse sentido. Ele diz, por exemplo, ser inegável que "a maneira pela qual a vida internacional afeta uma cidade qualifica-a tanto, e por vezes mais, quanto a sua ligação perene com as [cidades] que lhe são próximas. A história geral se sobrepõe a história local" (BRAUDEL, 1998b, p. 162). Contudo, embora afirmando isso, ele reconhece ser muito difícil "distinguir o vínculo entre a indústria particular considerada e o conjunto econômico que a envolve e do qual depende seu próprio movimento" (Op. Cit., p. 305 - grifos no original). Ora, esse conjunto pode dizer respeito a uma cidade, nação ou a um grupo de nações.

Pode-se, assim, estilizar o espaço da economia-mundo como subdividido em três tipos de áreas: o centro, a semiperiferia e a periferia. No centro localizam-se os elos mais rentáveis das cadeias globais e que exigem força de trabalho mais qualificada, representando níveis mais elevados de recompensas; a periferia abriga os elos menos lucrativos das cadeias mercantis e onde laboram trabalhadores pouco qualificados, com reflexos nas recompensas. A característica da semiperiferia é apresentar uma mescla de elos que exigem maior qualificação com elos que demandam baixa qualificação. É importante observar que na ausência de um mecanismo central no sistema mundial, que distribua de forma mais igualitária a execução das tarefas, as forças de mercado acabam por reforçar as desigualdades dentro do sistema mundial, num tipo de processo que Gunnar Myrdal talvez chamasse de “causação circular cumulativa” (MYRDAL, 1960).

Portanto, na perspectiva das economias-mundo, as cadeias mercantis globais são os principais determinantes, na verdade a "ossatura", do sistema mundial. Assim consideradas, são ingrediente central na análise da trajetória histórica do capitalismo, na linha explorada pelos autores da economia política dos sistemas-mundo, utilizados nesta sub-seção. Todavia, a correspondente noção é também utilizada em abordagens sobre dinâmicas produtivo-territoriais contemporâneas, particularmente levando em conta os desafios e possibilidades representados pela globalização.

\section{CONSIDERAÇÕES FINAIS}

Conforme assinalado, o enfoque das cadeias mercantis globais apresenta-se útil à análise da dualidade global/local. Além disso, torna possível 
visualizar a maneira como países e regiões são envolvidos e como participam nas redes transnacionais de produção e comércio. Um aspecto importante é que essa abordagem permite avaliar criticamente o paradigma do desenvolvimento endógeno, - tornado quase "hegemônico" no período atual - ao indicar que os atributos específicos de cada região, por melhores que possam ser em relação aos de outras regiões, não garantem que o principal das "recompensas" surgidas dentro de uma cadeia seja apropriado localmente. Por "recompensas" se está querendo referir, conforme já assinalado, a níveis de lucros e de salários, por exemplo.

Assim, talvez não seja difícil observar que a incorporação dos locais/ regiões na economia mundial, acontece sempre que se faz necessário recompor a "acumulação sem fim" de capital. Essa incorporação se traduz no acréscimo das atividades locais/regionais em cadeias mercantis globais que se caracterizaram quase sempre como atividades inferiores. Isso significa dizer que para as regiões não centrais da economia mundial, a inserção em uma, ou várias cadeias mercantis, pode, e geralmente acontece, de forma periférica, subordinada aos interesses de grandes corporações multinacionais.

Seja como for, a noção de cadeias mercantis globais permite colocar em termos sistêmicos a análise local/regional. Além disso, estamos sugerindo que, a região que participa, mesmo que de forma periférica, de uma cadeia mercantil global, caso venha a se recusar seguir as "regras" de funcionamento de tal cadeia, pode ser excluída da rede e por em risco a possibilidade de melhorar, ou até mesmo prejudicar, o seu desenvolvimento socioeconômico.

\section{ELEMENTS FOR AN ANALYSIS OF REGIONALIZATION VER- SUS GLOBALIZATION FROM THE GLOBAL COMMODITY CHAINS PERSPECTIVE}

\section{Abstract}

This article intends to, though modestly, provide some contributions and elements which could help in the understanding of the relationship between the local/regional level and the global level. In this way, the 
text presents initially two approaches to this relationship: one concerns what is called "endogenous and local development"; the other deals with "globalization". After that, the perspective of the global commodity chains is presented and discussed as an alternative approach. The main question that drives this discussion is: what could be the possible contributions of the conceptual framework in terms of global commodity chains to the debate concerning local/regional vs. global? Other questions are: to what extent, and how, regions participate in one or more global commodity chains? What does such integration mean to the regions involved? Formulated in these terms, the subject matter of the article reflects the understanding that, frequently, processes manifested and observed at the local and regional levels have to be connected to broad processes, which means that they should be seen as parts of larger dynamics, the actual dimensions of which normally transcend the local-regional level.

Keywords: local/regional; global; globalization; integration; global commodity chains.

JEL Classification: R10; R38

\section{REFERÊNCIAS}

ARRIGHI, Giovani. Globalização e macrossociologia histórica. In: Revista de Sociologia Política, Curitiba, p. 13-23, jun 2003.

AMIM, Ash.; ROBINS, Kevin. Regresso as economias regionais? In: In: BENKO, G.; LIPIETZ, A. (Orgs). As Regiões Ganhadoras: distritos e redes, os novos paradigmas da geografia econômica. p. 33-48, Celta Editora, Lisboa : 1994.

BAUMANN, Renato. Uma visão econômica da globalização. In: BAUMANN, Renato. O Brasil e a economia global. Rio de Janeiro : Campus: SOBEET. 1996. 
BENKO, George. Economia, espaço e globalização na aurora do século XXI. São Paulo: Hucitec, 1996. Cap. 1 e 3.

BENKO, George; LIPIETZ, Alain. O novo debate regional. In: BENKO, George; LIPIETZ, Alain (Orgs). As regiões ganhadoras: distritos e redes, os novos paradigmas da geografia econômica. p. 3-14, Lisboa : Celta, 1994.

BRANDÃO, Carlos A. Teorias, estratégias e políticas regionais e urbanas recentes: anotações para uma agenda do desenvolvimento territorializado. In: Revista Paranaense de Desenvolvimento, n. 107, p. 57-76, jul-dez. 2004. Disponível em: www.ipardes.gov.br

BRAUDEL, Fernand. Civilização material, economia e capitalismo: séculos XV-XVIII. Tomo 3: O tempo do mundo. $2^{\mathrm{a}}$ ed. São Paulo: Martins Fontes, 1998a.

GAROFOLI, Gioacchino. Os sistemas de pequenas empresas. In: BENKO, G.; LIPIETZ, A. (Orgs). As Regiões Ganhadoras: distritos e redes, os novos paradigmas da geografia econômica. p. 33-48, Lisboa : Celta Editora, 1994.

HOPKINS, T.; WALLERSTEIN, I. Commodity chains in the WorldEconomy prior to 1800. Review, X, 1, p. 157-170, Summer 1986.

HOPKINS, T.; WALLERSTEIN, I. Capitalism and the incorporation of new zones into the World-Economy. Review, X, n. 5/6, p. 763-779, Supplement (Summer/Fall) 1987.

HOPKINS, T. K.; WALLERSTEIN, I. Commodity chains: construct and research. In: GEREFFI, G.; KORZENIEWICZ, M. (Eds.). Commodity chains and global capitalism. London: Greenwood Press, 1994, p. 17-20.

KAPLINSKY. Raphael. Spreading the gains from globalisation: what cam be learned from value chain analysis? IDS Working Paper, Istitute of Developmente Studies, 2000. 
LINS, Hoyêdo Nunes. Regulação local: problemática e ensaio de observação. In: Ensaios FEE, Porto Alegre, v. 27, n. 1, p. 153-178, jan-jun 2006 a.

; ALVES, Pedro. A industria automobilística e o Brasil: uma abordagem na ótica das cadeias mercantis globais. In: $\mathrm{X}$ Encontro Nacional de Economia Política/SEP, Campinas Unicamp, maio 2005.

. Economia política do desenvolvimento: desigualdades sócio-espaciais na abordagem do sistema-mundo. VII ENCONTRO DE ECONOMIA DA REGIÃO SUL - ANPEC SUL 2005, jul. 2004, Maringá, Universidade Estadual de Maringá. Anais...(CD ROM).

. Promoção do desenvolvimento em escala territorial: uma abordagem com ênfase na experiência catarinense. In: Texto para Discussão. n. 6, Florianópolis, UFSC/CNM, 2003. Disponível em: http://www. cse.ufsc.br/ gecon/

. A questão regional na aurora do século XXI: os desafios da globalização. In: Ensaios FEE, Porto Alegre, v. 22, n. 2, jun-dez 2001.

. Globalização e integração econômica: impactos sócio-espaciais. In: VIGEVANI, T.; LORENZETI, J. (Orgs). Globalização e integração regional: atitudes e impactos sociais. São Paulo : LTr, 1998.

MYRDAL, Gunnar. Teoria econômica e regiões subdesenvolvidas. Rio de Janeiro. ISEB, 1960.

PECQUEUR, Bernard; SILVA, Mário Rui. Industrialização difusa e desenvolvimento. IREP, Cahier, ${ }^{\circ}$ 27, maio 1988

PERROUX, François. A economia do século XX. Lisboa : Livraria Morais Editora, 1967.

VÁZQUEZ BARQUERO, A. Desenvolvimento endógeno em tempos de globalização. Porto Alegre: Fundação de Economia e Estatística; Ed. Da UFGRS, 2001. 
WALLERSTEIN, I. EI moderno sistema mundial. Tomo I: La agricultura capitalista y los orígenes de economía-mundo europea en el siglo XVI. México: Siglo Veintiuno Editores, 1979.

. El moderno sistema mundial. Tomo II: El mercantilismo y la consolidación de la economía-mundo europea, 1600-1750. México: Siglo Veintiuno Editores, 1984.

. El moderno sistema mundial. Tomo III: La segunda era de gran expansión de la economía-mundo capitalista, 1730-1850. México: Siglo Veintiuno Editores, 1998.

. Capitalismo histórico e civilização capitalista. Rio de Janeiro: Contraponto, 2001.

WALLERSTEIN, I.; HOPKINS, K. Commodity chains in the worldeconomy prior to 1800. In: The essential Wallerstein. New York: The New York Press, 2000, p. 223-233.

Artigo submetido para publicação em janeiro de 2010 e aceito em junho de 2010. 